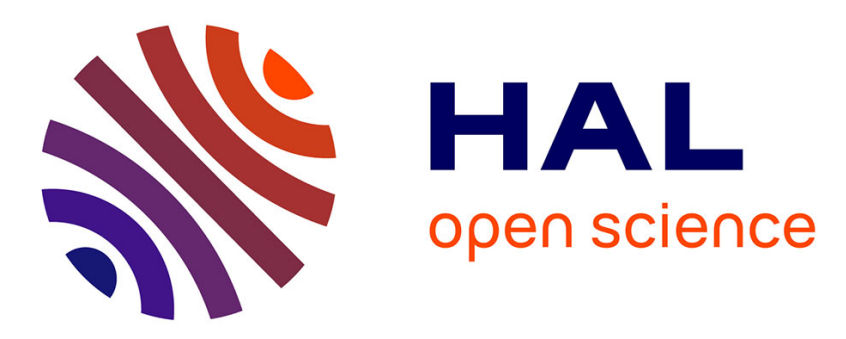

\title{
Enhanced reactivity of copper complex-based reactive materials via mechanical milling
}

Tao Wu, Florent Sevely, Sylvain Pelloquin, Sandrine Assié-Souleille, Alain Estève, Carole Rossi

\section{- To cite this version:}

Tao Wu, Florent Sevely, Sylvain Pelloquin, Sandrine Assié-Souleille, Alain Estève, et al.. Enhanced reactivity of copper complex-based reactive materials via mechanical milling. Combustion and Flame, 2021, 233, pp.111598. 10.1016/j.combustflame.2021.111598 . hal-03312787

HAL Id: hal-03312787

https://hal.laas.fr/hal-03312787

Submitted on 2 Aug 2021

HAL is a multi-disciplinary open access archive for the deposit and dissemination of scientific research documents, whether they are published or not. The documents may come from teaching and research institutions in France or abroad, or from public or private research centers.
L'archive ouverte pluridisciplinaire HAL, est destinée au dépôt et à la diffusion de documents scientifiques de niveau recherche, publiés ou non, émanant des établissements d'enseignement et de recherche français ou étrangers, des laboratoires publics ou privés. 


\title{
Enhanced Reactivity of Copper Complex-Based Reactive Materials via Mechanical Milling
}

Tao Wu, Florent Sevely, Sylvain Pelloquin, Sandrine Assié-Souleille, Alain Estève, and Carole Rossi $^{*}$

LAAS-CNRS, University of Toulouse, 7 Avenue du colonel Roche, 31400 Toulouse, France

\begin{abstract}
A prior investigation by the authors demonstrated that incorporating $25 \%$ of copper complex $\left(\mathrm{Cu}\left(\mathrm{NH}_{3}\right)_{4}\left(\mathrm{NO}_{3}\right)_{2}\right)$ into $\mathrm{Al} / \mathrm{CuO}$ nanothermite enables to produce highly-reactive gasgenerating energetic composites for emerging micro-airbag applications. To further improve the decomposition of the copper complex into gaseous species $\left(\mathrm{N}_{2}, \mathrm{O}_{2}, \mathrm{~N}_{2} \mathrm{O}\right)$, during the thermite reaction, we employed ball milling technique to diminish its grain size down to the nanoscale. Results show that premilling the copper complex i.e. refining its grains without much modifying their structures, increases the pressure generation and burn rate by a factor 1.5 and 2 , respectively. It also maintains a high degree of performances along a wider range of thermite to copper complex mass ratio.
\end{abstract}

\section{Introduction}

Ball milling is a well-established, inexpensive and scalable technique for fabrication of different powdered materials [1,2]. For energetic materials including metastable alloys, $\mathrm{Al} /$ oxides reactive materials ( $\mathrm{RMs}$ ), ball milling technique allows their reactive properties to be enhanced through nano-structuring of the material [1,3]. Indeed, the strong mechanical stresses appearing in the course of ball milling usually leads to a reduction of the grains sizes down to nanometric sizes, typically on the scale of $100 \mathrm{~nm}$, as well as an increase of the volume of the fraction of boundary regions $[1,4]$, which define the kinetics of material ignition $[1,5-$ 7]. Here, it is applied here to tune the size of copper complex, $\mathrm{Cu}\left(\mathrm{NH}_{3}\right)_{4}\left(\mathrm{NO}_{3}\right)_{2}$ (referred as to $\mathrm{CuC})$, mixed with $\mathrm{Al} / \mathrm{CuO}$ nanothermites to enhance the reactivity of the resulting gas generating material [8]. As synthesized, CuC particles contain large amount of big $(\sim 30 \mu \mathrm{m})$ and non-uniform particles provoking inhomogeneous mixing with $\mathrm{Al}$ and $\mathrm{CuO}$ components and deficient thermal transfer within the composite; thus, penalizing burn rate and gas production yield. We present in this communication the effect of milling process on the resulting internal microstructures of the milled $\mathrm{CuC}$ powder and combustion behavior. The results show that premilling $\mathrm{CuC}$ improves both the $\mathrm{RMs}$ preparation, usability range and reactive properties.

\section{Experimental}

$\mathrm{CuC}$ was synthesized according to literature [8]. The as-synthesized $\mathrm{CuC}(\mathrm{raw} \mathrm{CuC}$ ) were milled using a Retsch CryoMill machine with alumina grinding balls (diameter: $25 \mathrm{~mm}$ ). In each milling vial, raw materials and gridding balls occupy $1 / 3$ of the vial volume, respectively, leaving the rest $1 / 3$ volume with air. This volumetric ratio was used under the instruction of the milling machine. Milling parameters: $30 \mathrm{~Hz}$ (30/s) for various duration (3, 10 and $20 \mathrm{~min}$ ) with liquid $\mathrm{N}_{2}$ cooling. The milled powder (labelled as $\mathrm{CuC}^{\text {milled_milling time }}$ ) was then collected and stored in vials. The other experimental details are provided in supplemental file.

\section{Results and Discussion}

Figure 1a shows the X-ray diffraction (XRD) patterns of raw and milled CuC powders. It is observed that ball milling does not change its phase as the majority of the XRD peaks from

\footnotetext{
* Corresponding author.

E-mail address: rossi@1aas.fr (Dr. C. Rossi)
} 
both samples are aligned very well with the standard pattern of $\mathrm{Cu}\left(\mathrm{NH}_{3}\right)_{4}\left(\mathrm{NO}_{3}\right)_{2}(\mathrm{PDF} \# 01-070-$ 0195). The XRD patterns of milled $\mathrm{CuC}$ remain unchanged for various milling times. Some variations in peak intensities of these two XRD patterns are noticed (Figure 1a), such as (141) vs (240), (040) vs (101), (301) vs (321), etc. After comparison, it appears that the XRD pattern of milled $\mathrm{CuC}$ resembles the reference pattern more than the raw $\mathrm{CuC}$, which is likely affected by preferred orientation in raw $\mathrm{CuC}$ [9]. Preferred orientation is a measurement artifact caused by sample preparation and appeared more common in samples with distinct shape, such as the rod-shaped raw $\mathrm{CuC}$ (Figure S2), whereas milled $\mathrm{CuC}$ no longer features such shape but rather exhibits arbitrary morphologies. All in all, the milled $\mathrm{CuC}$ crystallites are more randomly oriented in the XRD experiment and therefore resembles the reference pattern more [9].

Peak broadening is spotted on peaks below $2 \theta 40^{\circ}$ in the pattern of milled samples (Table S1), which might suggest smaller crystallite sizes are formed upon milling [10,11]. The average crystallite size extracted from the broadening of all peak widths labeled in Figure 1a using the Scherrer equation is about $49 \mathrm{~nm}$ for milled powder, versus $56 \mathrm{~nm}$ for raw ones $[12,13]$. Obviously, the milling does not pose much effect on reducing the crystallite size; but, importantly, it does affect the particle size significantly.

Figure 1b-j shows the SEM images of the three milled CuC. Indeed, the particle sizes of these milled samples decreased significantly (spanning from 1 to $10 \mu \mathrm{m}$ ) after milling comparing with the raw $\mathrm{CuC}$ rod-shaped particles $(\sim 20 \mu \mathrm{m}$ in width and $\sim 60 \mu \mathrm{m}$ in length, see SEM images in Figure S2). It is clearly shown that the milled $\mathrm{CuC}$ particles feature no longer the rod-looking shapes but rather irregular profiles within micro-sized ranges. As observed in Figure $1 \mathrm{~b} / \mathbf{1 e} / \mathbf{1 h}$, there are still some particles larger than $5 \mu \mathrm{m}$ remain existence after 3 minutes milling; when the milling is prolonged to 10 and 20 minutes, the $\mathrm{CuC}$ paticles' size is mostly around $1 \mu \mathrm{m}$. In other words, longer milling time gives smaller particles size. In addition to reducing particles sizes, mechanical milling also develops more textures in micro/nanoscales (Figure 1f-g and 1i-j) on the surface of $\mathrm{CuC}$ milled for longer than 10 minutes when comparing to the smooth surface morphology of raw $\mathrm{CuC}$ rods. Such detailed textures could be resulted from fracturing/cracking of $\mathrm{CuC}$ particles induced by mechanical milling. The richness of the surface texture could potentially increase its surface area to promote a better contact with other components in the RMs. In fact, the corresponding BET measurements demonstrates an increase in the specific surface area of CuC powders after milling, $\sim 0.7 \mathrm{~m}^{2} / \mathrm{g}$ for raw $\mathrm{CuC}$ to $\sim 3 \mathrm{~m}^{2} / \mathrm{g}$ for $\mathrm{CuC}$ milled by 3 minutes.

The temporal pressure records of different $\mathrm{CuC} / \mathrm{Al} / \mathrm{CuO} \mathrm{RMs}$ are presented in Figure S3. The pressure developed by $\mathrm{Al} / \mathrm{CuO}$ thermite is included for the purpose of literature comparisons. Pressure peak values normalized per unit mass of the burnt materials are compared for different milling times in Figure 1k. The effect of milling is clearly established: regarding the maximum pressure, $\mathrm{CuC}$-containing $\mathrm{RMs}$ with milled $\mathrm{CuC}$ outperform those with raw $\mathrm{CuO}$ by $\sim 45 \%$. $\mathrm{CuC}^{\text {milled_3min }} / \mathrm{Al} / \mathrm{CuO}$ features the highest increase $(\sim 52 \%)$ while the difference among all three milled composites can be neglected if we consider the experimental deviations. For pressurization rate, the trend is quite similar to the maximum pressure results, except $\mathrm{CuC}^{\text {milled_lomin }} / \mathrm{Al} / \mathrm{CuO}$ gives the fastest rate. But, again, the influence of the milling time is quite negligible.

Burning rate experiments, reported in Figure 11 and Video S1, give a similar trend. $\mathrm{CuC}^{\text {milled_10min }} / \mathrm{Al} / \mathrm{CuO}$ features the highest velocity: $150 \mathrm{~m} / \mathrm{s}$ against $85 \mathrm{~m} / \mathrm{s}$ from CuC/Al/CuO (roughly $80 \%$ improvement) and $50 \mathrm{~m} / \mathrm{s}$ for $\mathrm{Al} / \mathrm{CuO}$ thermite system. $\mathrm{CuC}^{\text {milled_3min }} / \mathrm{Al} / \mathrm{CuO}$ shows the smallest enhancement on propagation speed, possibly because the particles sizes of $\mathrm{CuC}^{\text {milled_3min }}$ are larger than the other two milled powders. Note that the optimal milling time, $10 \mathrm{~min}$, for burning rate follows that of the pressurization rate rather than the maximum 
pressure. In fact, there is not much difference between the propagation speeds of $\mathrm{CuC}^{\text {milled_lomin }} / \mathrm{Al} / \mathrm{CuO}$ and $\mathrm{CuC}^{\text {milled_20min }} / \mathrm{Al} / \mathrm{CuO}$; with the uncertainty bars, it seems that a longer milling time than 10 minutes does not further improve the propagation speed significantly.

Moreover, as we recall that $\mathrm{Al} / \mathrm{CuO}$ to $\mathrm{CuC}$ mass ratio highly affects the self-combustion capabilities of $\mathrm{CuC} / \mathrm{Al} / \mathrm{CuO} \mathrm{RMs}$ [8]. We found that the optimized weight percentage (wt\%) of $\mathrm{Al} / \mathrm{CuO}$ allowing a self-sustained decomposition of $\mathrm{CuC}$, faster burn rate and maximum enhancement on peak pressure was $75 \%$. For $\mathrm{Al} / \mathrm{CuO}_{w t} \%$ belows $75 \%$, the $\mathrm{CuC} / \mathrm{Al} / \mathrm{CuO}$ combustion properties rapidly declines. When $\mathrm{Al} / \mathrm{CuO}_{w t} \%$ drops to $50 \%$, the flame propagation was measured at $3 \mathrm{~m} / \mathrm{s}$ and the flame quenches when $\mathrm{Al} / \mathrm{CuO}_{w t} \%$ reaches $25 \%$ : not enough thermite is in the system to sustain the $\mathrm{CuC}$ heating to its decomposition temperature $\left(260{ }^{\circ} \mathrm{C}\right)$. In our previous article, the reaction mechanism of $\mathrm{CuC} / \mathrm{Al} / \mathrm{CuO}$ was detailed: $\mathrm{Al} / \mathrm{CuO}$ ignites locally and the generated heat promotes decomposition of $\mathrm{CuC}$; then the decomposition products of $\mathrm{CuC}$ further participate in $\mathrm{Al} / \mathrm{CuO}$ thermite reaction [8]. Not only behaving as a gas generator, $\mathrm{CuC}$ also acts as the heat transfer medium within the RMs. Since $\mathrm{CuC}$ has a thermal conductivity lower than $\mathrm{Al} / \mathrm{CuO}$ thermite, it could potentially act as hot points in the composite to increase local temperatures and enhance the overall reactivity, similar to the previous published works on the positive effects of silica/gold additions in RMs [14,15].

Thus, premilling $\mathrm{CuC}$ offers opportunity to take advantage of the spreading of smaller and denser hot points within the composite that empower it with a higher capability to rise in temperature. This is particularly visible for $\mathrm{Al} / \mathrm{CuO}_{w t} 50 \%$ : while this corresponds to a propagation limit at $3 \mathrm{~m} / \mathrm{s}$ for $\mathrm{CuC} / \mathrm{Al} / \mathrm{CuO}$ using raw $\mathrm{CuC}, \mathrm{CuC} / \mathrm{Al} / \mathrm{CuO}$ with premilled $\mathrm{CuC}$ (10 min) still propagate at a high velocity: $120 \mathrm{~m} / \mathrm{s}$ (Video S2), which represents a gain of two order of magnitudes in the burn rate. Only decreasing $\mathrm{CuC}$ particles sizes, the propagation of $\mathrm{CuC} / \mathrm{Al} / \mathrm{CuO}$ improved extraordinarily due to the following two factors: 1) the thermal transfer between $\mathrm{CuC}$ and $\mathrm{Al} / \mathrm{CuO}$ thermite is considerably improved after milling; 2) more $\mathrm{CuC}$ hot spots are spread within the RMs. Both factors facilitate the decomposition of $\mathrm{CuC}$ and heat transfer efficiency, thus accelerate the flame propagation.

Then, decreasing $\mathrm{Al} / \mathrm{CuO}_{w t} \%$ down to $25 \%$ still leads to quenching of the reaction as in the case of $\mathrm{CuC} / \mathrm{Al} / \mathrm{CuO} \mathrm{RMs}$ prepared with raw $\mathrm{CuC}$. This was expected as reducing the size of grains down to the nanoscale does not modify the thermal energy necessary to heat up the material to its decomposition temperature. 

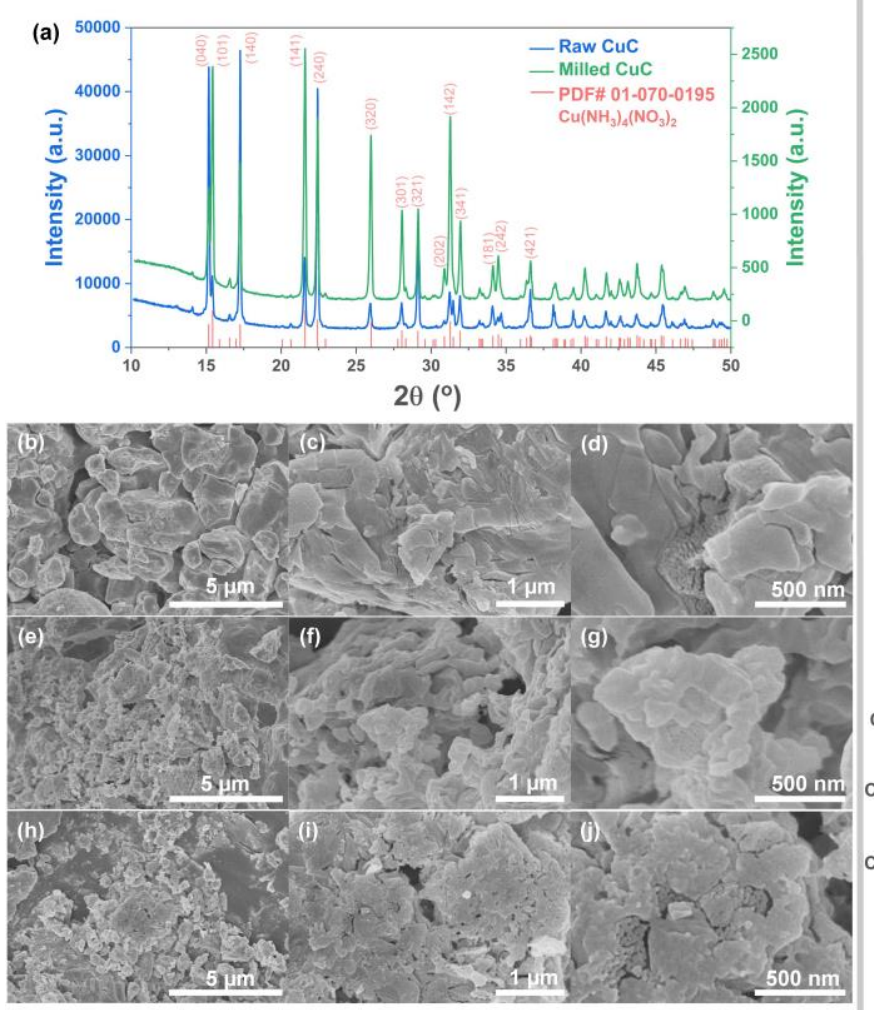

(k)
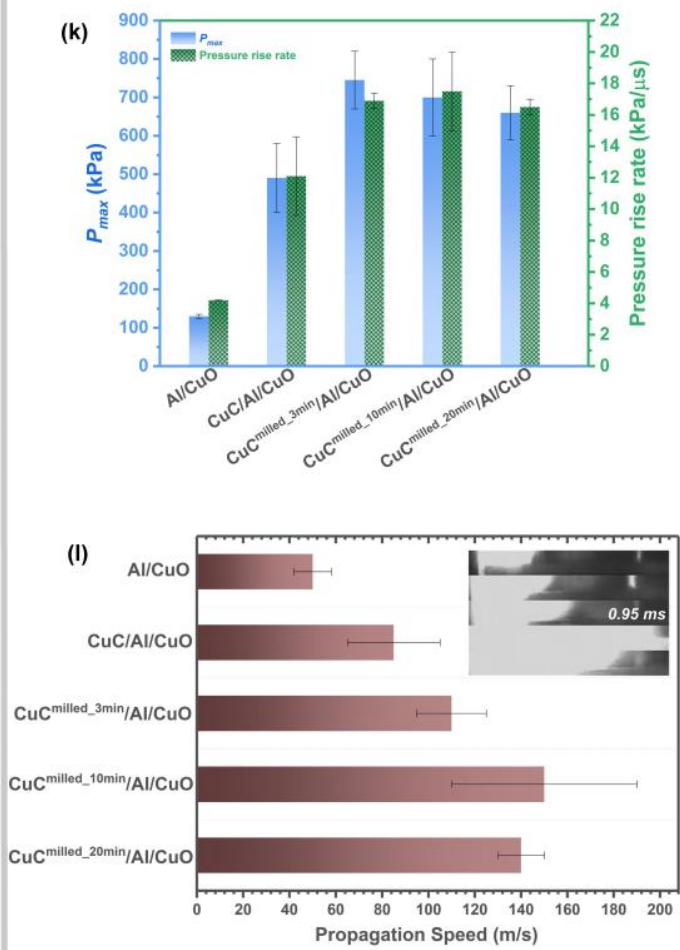

Figure 1. (a) XRD patterns of milled $C u C$ in comparison to raw $C u C$; SEM images of $C u C$ milled by $3(b-d), 10(e-g)$, and 20 minutes $(h-j)$; maximum generated pressure and pressure rise rate ( $k$ ), and propagation speed results (l) of different $\mathrm{CuC/Al/CuO} \mathrm{RMs}$. The inset image in (l) is a snapshot from the propagation test videos of these five materials at $0.95 \mathrm{~ms}$ (see supplement, Video S1).

\section{Competing financial interests}

None.

\section{Acknowledgements}

The authors acknowledge support from the European Research Council (H2020 Excellent Science) Researcher Award (grant 832889 - PyroSafe) and the Occitanie Region / European Union for their FEDER support (THERMIE grant). This work was also supported by LAASCNRS technology platform, a member of Renatech network. We acknowledge the help from Christophe Tenailleau and Marie-Claire Barthélémy from CIRIMAT for performing XRD and BET measurements.

\section{Supplementary materials}

Supplementary materials associated with this article are available in a separate document.

\section{References}

[1] C. Badiola, M. Schoenitz, X. Zhu, E.L. Dreizin, Nanocomposite thermite powders prepared by cryomilling, J. Alloys Compd. 488 (2009) 386-391. https://doi.org/10.1016/j.jallcom.2009.08.146.

[2] C. Woodruff, E.R. Wainwright, S. Bhattacharia, S.V. Lakshman, T.P. Weihs, M.L. Pantoya, Thermite reactivity with ball milled aluminum-zirconium fuel particles, Combust. Flame. 211 (2020) 195-201. https://doi.org/10.1016/j.combustflame.2019.09.028. 
[3] M. Schoenitz, T.S. Ward, E.L. Dreizin, Fully dense nano-composite energetic powders prepared by arrested reactive milling, Proc. Combust. Inst. 30 (2005) 2071-2078. https://doi.org/10.1016/j.proci.2004.08.134.

[4] H. Wang, J.B. DeLisio, T. Wu, X. Wang, M.R. Zachariah, One-step solvent-free mechanochemical synthesis of metal iodate fine powders, Powder Technol. 324 (2018) 62-68. https://doi.org/10.1016/j.powtec.2017.10.024.

[5] S.M. Umbrajkar, S. Seshadri, M. Schoenitz, V.K. Hoffmann, E.L. Dreizin, Aluminum-Rich AlMoO3 Nanocomposite Powders Prepared by Arrested Reactive Milling, J. Propuls. Power. 24 (2008) 192-198. https://doi.org/10.2514/1.31762.

[6] M. Schoenitz, T. Ward, E.L. Dreizin, Preparation of Energetic Metastable Nano-Composite Materials by Arrested Reactive Milling, MRS Online Proc. Libr. 800 (2003) 103-108. https://doi.org/10.1557/PROC-800-AA2.6.

[7] E.L. Dreizin, M. Schoenitz, Mechanochemically prepared reactive and energetic materials: a review, J. Mater. Sci. 52 (2017) 11789-11809. https://doi.org/10.1007/s10853-017-0912-1.

[8] T. Wu, F. Sevely, B. Julien, F. Sodre, J. Cure, C. Tenailleau, A. Esteve, C. Rossi, New coordination complexes-based gas-generating energetic composites, Combust. Flame. 219 (2020) 478-487. https://doi.org/10.1016/j.combustflame.2020.05.022.

[9] J.K. Cockcroft, A.C. Jupe, Preferred Orientation, Adv. Certif. Powder Diffr. Web. (1997). http://pd.chem.ucl.ac.uk/pdnn/pdindex.htm.

[10] T. Ungár, Microstructural parameters from X-ray diffraction peak broadening, Viewp. Set No 35 Met. Alloys Struct. Scale Micrometer At. Dimens. 51 (2004) 777-781. https://doi.org/10.1016/j.scriptamat.2004.05.007.

[11] R. Yogamalar, R. Srinivasan, A. Vinu, K. Ariga, A.C. Bose, X-ray peak broadening analysis in $\mathrm{ZnO}$ nanoparticles, Solid State Commun. 149 (2009) 1919-1923. https://doi.org/10.1016/j.ssc.2009.07.043.

[12] T. Wu, P.Y.Zavalij, M.R. Zachariah, Crystal structure of a new polymorph of iodic acid, $\delta$-HIO3, from powder diffraction, Powder Diffr. 32 (2017) 261-264. https://doi.org/10.1017/S0885715617000859.

[13] V. Uvarov, I. Popov, Metrological characterization of X-ray diffraction methods for determination of crystallite size in nano-scale materials, Mater. Charact. 58 (2007) 883-891. https://doi.org/10.1016/j.matchar.2006.09.002.

[14] H. Wang, J.B. DeLisio, S. Holdren, T. Wu, Y. Yang, J. Hu, M.R. Zachariah, Mesoporous Silica Spheres Incorporated Aluminum/Poly (Vinylidene Fluoride) for Enhanced Burning Propellants, Adv. Eng. Mater. 20 (2018) 1700547. https://doi.org/10.1002/adem.201700547.

[15] B. Julien, J. Cure, L. Salvagnac, C. Josse, A. Esteve, C. Rossi, Integration of Gold Nanoparticles to Modulate the Ignitability of Nanothermite Films, ACS Appl. Nano Mater. 3 (2020) 2562-2572. https://doi.org/10.1021/acsanm.9b02619. 